\title{
A CRIANÇA NO CONTEXTO FAMILIAR
}

\author{
Ada Pellegrini Lemos ${ }^{1}$
}

LEMOS, A. P. A Criança no Contexto Familiar. Rev. Bras. Cresc. Des. Hum.1(2): 1991.

\section{RESUMO}

Através da exposição de uma sessão de Terapia Familiar, a autora procura evidenciar a existência de uma trama inconsciente regendo as relações familiares e determinando a qualidade da dimensão afetiva que envolverá, fatalmente, a criança e, futuramente, o adulto em sua própria família de origem.

Este estudo é uma tentativa de se caracterizar o que ocorre com urna criança, em função das suas relacões com a família e dentro dela.

Partindo-se de falos comuns a todas as pessoas, tentar-se-á elucidar o conceito da trama existente em todas as famílias, que pode levar a resultados inesperados, podendo modificar totalmente o rumo da vida de uma criança.

Anteriormente a Freud, as pessoas eram definidas pelo que falavam, pelo que exteriorizavam através das suas palavras. Sua aparência e essência confundiam-se, de uma certa maneira. Somente os artistas, cantores e escritores, como Shakespeare, por exemplo, é que, intuitiva e sensitivarnente, conheciam a alma humana, suas profundezas, em seus mais íntimos recônditos.

Mas é somente depois de Freud, marco fantástico para a compreensão da mente humana, com suas idéias e seus conceitos, que as pessoas não serão consideradas, ou, ainda, conhecidas apenas pela sua aparência. E esta não mais revela o ser de um ser humano.

Freud descortina, então, a possibilidade de um mundo inteiro e imenso no interior de cada um, com potencialidades, conflitos, riquezas e recursos próprios. Um mundo de outras dimensões que a linguagem verbal não esgota, nem explica toda sua amplitude. Assim, temse, por exemplo, uma mulher exercendo, den- tro de um grupo familiar, o papel de mãe, mas que, dentro de si mesma, em sua realidade mais íntima, é uma rival dos seus filhos e não exatamente sua mãe.

O mesmo poderia se dar com um homem que, mesmo investido no papel de pai, vê no filho um inimigo, ainda que essa criança seja um bebe. Para este homem, seu filho é tão-somente outro ser humano que, pelo simples falo de existir, já lhe representa uma grande ameaça, pois, de acordo com Freud, o inconsciente não tem lei, nem tempo e nunca, lógica.

Partindo destas e de outras considerações, que demonstraram as relações das profundezas da vida mental rnanifestadas e estudadas por Freud no adulto, outras perspectivas foram descobertas por analistas ingleses, liderados por Melaine Klein, nas quais ficou provado que, ao nascer, o bebe já guarda consigo uma intensa vida mental. E, talvez brevemente, chegue-se ao interior da vida mental uterina, do que carrega o ser humano em seu universo intro-uterus.

Frente a essas conclusões e tomando-as por base, pode-se dizer, numa primeira abordagem, que toda família, apesar de ter uma aparência bemestruturada, guarda, intrinsecamente, uma trama de relações inconscientes, na qual os Depois tradicionais, rezados pela cultura, de pai-mãe-filhofilha, etc., não se dimensionam, necessariamente,

1 Doutora em Serviço Soaal, professora do Programa de Estudos Pós-Graduados em Serviço Social, coordenadora do Pmgrama de Especialização em Famílias: "Família - dinâmica e processos de mudança”, da PUC/SP, terapeuta familiar. Av. dos Tajurás, 406 - CEP 05670 - Cidade Jardim - São Paulo - SP - Fone. (011) 814-1732. 
desta forma. Ao contrário: podem tomar configurações totalmente diversas e antagônicas.

Para esclarecer melhor o que sejam essas diferentes relações e como esta trama se desvelo, segue-se, agora, a apresentação de um relatório de uma primeira sessão de terapia familiar, ocorrida há cinco anos, mas marcante o suficiente para a compreensão, num primeiro momento, das idéias encerradas neste estudo. O que a torna muito interessante não é meramente o que é dito, mas o seu desenrolar na sessão, seu enredo, o que está sendo articulado por trás do que está sendo falado, ficará muito nítido que as palavras são sempre iguais e que o mundo mental apresenta dimensões outras que a palavra não esgota.

São quatro os elementos desta família: A, a mãe, com 53 anos de idade; J, o pai, com 63 anos; CH, 21 anos, estudante de farmacologia e identificado pela família como o paciente a ser cuidado; e N, com 24 anos, estudante de engenharia, sendo os dois filhos do sexo masculino. A família é de origem israelita.

Adentram o consultório. CH senta-se ao lado da mãe; J senta-se num sofá e $\mathrm{N}$ em outro. Tem-se, então, dois pares: a mãe e $\mathrm{CH}$, o pai e o outro filho. A, a mãe, toma a palavra:

"Viemos porque aconteceu um acidente muito grave com $\mathrm{CH}$ e a Dra. $\mathrm{M}$ esteve com todos nós. Nós a procuramos e ela achou que seria melhor fazermos uma terapia familiar”.

A, sentada à beira do sofá, é uma senhora muito branca, gorda, de poucos e rotos cabelos, trazendo sequelas resultantes de um provável derrame. Quando pergunto o que aconteceu, ela chora, senta-se ainda mais à beira do sofá e entra em pranto convulso. A pergunta é-lhe novamente dirigida, à qual ela então atende:

CH tentou suicídio. Eu fui acordá-lo, de manhã, como sempre faço... Muitas vezes ele brincou e fez de conta que estava morto; mas eu achei que estava demais e mexi nele e vi que estava muito mole. Gritei e chamei o N, ele olhou o olho dele e chegamos até a pensar em droga. Aí, o N viu os comprimidos ao lado do criado-mudo e disse que deveríamos ir correndo ao Pronto-Socorro".

$\mathrm{N}$ : "Eu olhei e vi que a caixa estava vazia e, como moramos na Av...., logo pensei no Pronto-Socorro... e aí chamei o papai e todos fomos para lá”.

A pergunta: “Qual comprimido você, $\mathrm{CH}$, tomou e quantos foram?”, $\mathrm{CH}$ disse: "Eu tomei 40 comprimidos de Diempax".

A: "O médico disse que o perigo dele morrer se deu até as 3 horas da manhã, quando na acão da droga”.
$\mathrm{N}$ : "Nem adiantava mais fazer lavagem no estômago. Ele só tomou soro”.

A (caindo novamente em prantos): "Eu sou culpada. Não adianta. Tenho amigos que dizem que errei. Paciência, mas eu não aguento. Eu acho que prendi muito o $\mathrm{CH}$, eu protegi, não sei...”.

$\mathrm{J}$ é um homem baixo, obeso, de cabelos vermelhos, cortados à escovinha. Às palavras de sua esposa, precipita-se para a beira do sofá, volta-se para ela e fala:

"Bem, será que você me deixa falar, ou não? Até agora eu não falei, existe um pai, ou não? Pra que eu estou aqui?”.

Ele se volta para o restante do grupo e diz:

“O negócio é o seguinte: eu vou lhe ser muito sincero, sincero e muito franco. Posso até lhe ofender, mas não me importa nenhum pouco. Eu não gosto dessa história de psiquiatra, psicólogo, parapsicólogo. Esses dois, aí, se tratam com a Dra...., eu gostei muito dela e do Dr....”.

$\mathrm{CH}$ interfere:

"Eu faço individual, com Dr.... e ele foi até a minha casa no dia do suicídio e depois nós estivemos todos com a Dra. M”.

$\mathrm{J}$ : "Bom, eles foram atenciosos e disseram que o $\mathrm{CH}$ deu como um grito de alerta. Pode ser, eu acho que é possível. Mas eu penso que vocês, aí, psicólogos, ganham dinheiro à custa dos sofrimentos dos outros! Nós precisamos sofrer pró vocês ganharem dinheiro. Eu não gosto disso”. Seu pensamento é completado pela frase: “... como um urubu na carniça”, dita pela terapeuta, ao que $\mathrm{J}$ responde:

"É. Isso mesmo. Mas eu vim. Porque a senhora acha que é brincadeira ter um filho que tentou suicídio? Ele podia ter morrido!”.

Todos param um minuto, ficam muito quietos e a terapeuta aguarda. J rompe o silêncio:

"Eu quero continuar dizendo que nós somos uma família, mas eu sinto que cada um fica no seu mundo, não tem contato um com o outro. Não falamos, não conversamos, quase; não se sabe muito um do outro. Sé moramos juntos, nada mais. Acho que moramos no mesmo teta, só”.

A: "A Dra.... acha que foi um pedido de socorro e eu acho que foi”. E torna a chorar muito, novamente. A terapeuta volta-se e pergunta:

"E você, N, como vê a situação? E como viu a tentativa de suicídio do seu irmão?”.

N responde: "Eu fiquei gelado".

Enquanto isso, todos estavam de olhar fixo no paciente identificado. Ele estava muito vermelho, humilhado, olhos lacrimejantes, denotando um sofrimento muito grande.

$\mathrm{N}$ continua seu relato: "Eu fiquei gelado. Quando eu me vi no carro, voltando para casa, pra pegar o talão de cheques...”. 
A: "Na correria, nós o esquecemos e, no entanto, estava na minha bolsa”, interrompe a mãe.

N retoma: "Eu estava dizendo que eu não sei explicar o que senti. Eu sempre achei que o $\mathrm{CH}$ talvez pudesse fazer isto. Minha própria mãe, muitas vezes, lamenta-se da vida e já falou várias vezes em morrer".

$\mathrm{CH}$ manifesta-se: “A Dra. $\mathrm{M}$ acha que eu fui como que um menino travesso, mas eu não sei, eu não sei. Eu também não sei porque eu deixei a caixa pra eles verem”.

J confessa: "Eu fui como $\mathrm{CH}$, quando menino e moço. Eu me sentia inseguro, mas acho que isso passa... Eles são filhos e rapazes de 6tima saúde, bonitos e maravilhosos, temos que seguir em frente".

A terapeuta, olhando para os dois jovens, pergunta: "Vocês concordam com o papal?”. tamente".

Ao que eles, de pronto, negam: "Absolu-

$\mathrm{N}$ toma, então, a palavra. "Ele não quer, ele nunca quis ver nada”.

A terapeuta retoma: "Sabe, J, acho que você olha um aspecto para suportar ou negar o outro, presente nessa família Acho e sinto que todos vêm, há tempo, se sentindo isolados e deprimidos. Há muita depressão em todos, aqui. Eu não vou falar com a sua cabeça, J, mas com o que você sente. Considero $\mathrm{CH}$, o seu aio, a expressão dessa depressão em todos, aqui dentro”.

$\mathrm{N}$ : "Sabe, pai, acho que se CH tivesse falado isto, nós não irfanios acreditar. Então, ele fez. Assim, todos nós vimos”.

A terapeuta pergunta: “Que acha, CH?”

$\mathrm{CH}$ : "Eu não sei bem por que eu fiz. Mas há muito que eu venho me sentindo que não presto, que eu não vou conseguir nada, que eu não tenho nenhum valor. Em casa, eu não sei, eu não consigo fazer as coisas".

J: "Eu me sentia assim, de moço: abandonado. Principalmente porque as minhas duas irmãs eram mulheres, ganhavam o que queriam e tinham uma preferência clara do meu pai. Eu entendo ele, eu entendo. Eu também era sensível”.

$\mathrm{CH}$ : "Mas eu acho que em casa acontece uma coisa que eu não sei explicar. Eu sempre quis imitar o N, ele sempre se sai bem”.

$\mathrm{N}$ : "Eu nunca fui um bom estudante, mas eu sinto que meus pais não se importam, parece até o contrário, como se fosse bom. Mesmo assim, eles parecem que aprovam ou gostam ainda mais".

A: "O CH é esforçado, estuda muito. Mas parece que nem sempre consegue...”.

CH: "Eu não consigo, não. Quase sempre, não. Aí, eu tento agir como ele e me dou mal. Aí eu fracasso de uma vez, eu não sei, eu não sei o que fazer”.

$\mathrm{J}$ : "Eu acho que ele, N, sempre foi esperto, sabia agradar a gente”.

A completa, sorrindo: “Quando eu ia bater nele, de pequeno, ele ia contra a parede, levantava as mãozinhas e dizia: 'Ah! Mamãe! Que coisa triste que você vai fazer... Vai me bater? Você tem coragem?' Eu, ai, parava”.

J interrompe, sem a menor cerimónia, mudando de assunto: "E ela, ai, também teve um problema com o irmão e não foi fácil”.

A retruca, nervosa: "Você não pode falar no meu lugar! Eu explico: o que acontece é que meu pai era um homem muito delicado e até carinhoso, mas machista. A preocupação dele era o futuro do meu único irmão, que era homem. Ele sempre procurou fazer o meu irmão viajar, estudar. Oferecia tudo a ele! Ele deixou até que eu fizesse advocacia! Acho que era até avançado para a época. Afinal, foi no começo do século! Agora, a minha mãe era uma tola, não tinha opinião. E eu fiquei meio às traças, nunca acreditaram muito em mim. Mas, no entanto, e ainda hoje é assim, é comigo que todos vêm chorar as mágoas, eu sou a forte, o que pensam que é a forte, a que aguenta. Quando meu irmão queria, por um tempo, se desquitar, vinha na minha casa e chorava como criança! Pensam que eu sou forte, mas eu não sou nada disso!”.

Novamente, A cai num choro convulsivo. A terapeuta se manifesta:

"Vejam, eu queria realçar o seguinte: aqui ocorre um processo; não há culpados, não há inocentes. Aqui, alguém gera alguma coisa no outro. Vou aproveitar o que aconteceu aqui. Neste momento, CH parece representar, ou está deslocado para o $\mathrm{CH}$ justamente essa menina sem valor-e apontando A-, este homem sem valor-e apontando J-, estão colocados nele. Você, A, toma conta deste seu abandono nele e assim o enfraquece. E você, J, se afasta, por que ele mostra uma parte que lhe faz sofrer. Agora, entrando diretamente, eu diria: acho que você, $\mathrm{CH}$, e você, N, ficaram sem saida. Eu vou explicar por quê. Você, $\mathrm{CH}$, não pode ser ele porque não o é; e, quando se esforça aqui, nesta família, é como se fosse a prova de sua inferioridade e de sua incapacidade. Esforço, aqui, não é visto como valor. E então, como fica? Se trabalha, ou estuda, ou se esforça, é ameaçador; se o imita, é pior. Então, você não sabe como fazer para crescer”.

Nesse momento, a mãe interfere: "É, eu entendi o que a senhora quer dizer, eu entendi. Eu me aproximei dele por isso".

J: "É, a senhora é mesmo direta".

N: "Mas não ficou bem pra mim”. 
Terapeuta: "Eu acho que ficou péssimo. Você parece conseguir uma aprovação tão fácil pró tudo que você faz, que você fica sem saber se é válido ou não, se você é realmente de valor ou não. Os dois acabam num processo sem poder guardar forças e qualidades”. os outros?”.

$\mathrm{N}$ : “E por isso que eu acho que eu engano

Terapeuta: "Eu acho".

E a sessão foi encerrada.

Aparentemente, não há, neste relato, a existência de criança alguma. Mas, analisando-se o caso mais profundamente, há a pró sença marcante, intrínseca, de uma criança que não cresceu: A.

A análise deste feto clínico levará a um primeiro entendimento do que seja a trama familiar, porque, apesar de esta sessão ter ocorrido há mais de cinco anos, o problema nela contido 6 atemporal e pode estar acontecendo agora, em qualquer famílias em algum lugar.

Fica claro que, quando N, o filho mais velho, nasceu, já estava prescrito, de alguma maneira, quem ele seria. Quando $\mathrm{CH}$ nasceu, também já estava determinado o que e quem ele seria A família já havia vaticinado os papéis subliminares que cada um ocuparia dentro dela e na vida através do mecanismo da pseudo-identidade, que é colocado pela família na criança em desenvolvimento.

Esse mecanismo é muito forte e se incrusta de tal maneira na criança que ela desenvolve uma personalidade que não é a sua

É nessa medida que a história relatada é de extrema importancia para a compreensão da trama familiar, uma vez que se viu, claramente, o ápice de um desdobramento corr^^\}e,cado há vinte anos.

É exatamente neste ponto que ' se pode fazer o desmascaramento iniciado por Freud e continuado por Melaine Klein e tantos outros, tornando claro o conceito da trama: é o desmascaramento da mãe, A.

Nesta família, A é só mãe? Ela tem função de mãe; como em todas as famílias (o que é interessante) exerce prendas domésticas, sem a menor dúvida, mas não é só mãe. Ela é, sim, mãe de um bebe eterno, que el,a não consegue deixar crescer, provavelmente por medo. Ela sé identifica projetivamente com esta criança e, portanto, não consegue deixar de tomar conta de si própria, tomando conta do filho. Ela não se permite crescer, através do próprio filho.

Dessa maneira, ela vai destilando, através da identificação projetiva, a incapacidade de $\mathrm{CH}$, sua fragilidade, que ele é suscetível e não pode progredir. Essa destilação é feita ao longo dos anos, incessantemente. Daí a incrustação da pseudo-identidade em $\mathrm{CH}$.

Do filho N, o mais velho, vê-se que ela não é mãe. Ela é uma namorada. O casal real desta família é A e N. Foi N quem ela chamou, N quem foi atrás do talão de cheques, foi ele quem decidiu sobre o Pronto-Socorro, foram os dois, juntos, chamar o pai, J.

Essa postura de $\mathrm{N}$ é tão patente, dentro da família, que J entra na sessão e protesta: "Como? Não tem o pai?”, escondendo que ele, realmente, não é o pai. "Eu me acuso, antes que me acusem, pra que ninguém descubra o que ocorre com minha pessoa”, é o que grita seu inconsciente, não com medo de algum julgamento, mas em consequência do próprio conflito que nele se estabelece.

Se um psicólogo julgar uma família, ou uma pessoa, seu trabalho se tornará impossível. Sua escala de valores tem de ser posta de lado, pois, através deles, todo seu trabalho se inviabilizaria e ele não chegaria a nada.

Voltando à análise da sessão relatada, o quadro que se afigura é o seguinte: Apesar de reclamar seu lugar, J, o pai, sai de seu papel e o entrega a $\mathrm{N}$, pois também quer ceder seu lugar de pai ao filho. Assim, a mãe torna-se o centro das decisões: ela faz uma parelha com o filho mais velho, expulsa o marido e protege o filho caçula. O pai também joga os filhos para ela, pois há um pacto entre ele e a mãe, no qual os dois falam a verdade e satisfazem suas mútuas necessidades. J não se aproxima de $\mathrm{CH}$ porque ele é o seu retrato dentro da família e diante do filho mais velho, principalmente. A não deixa J entrar. J não entra e A entra. Ela entra e ele sai, e assim o jogo continua por anos e anos, até que a trama se forma, confinando e congelando as pessoas.

Nessa medida, a partir do momento em que nasce, a pessoa já está absolutamente congelada. Isso se percebe em falos sutis, como quando uma criança chora três noites seguidas, e algum membro da família diz: "É, eu acho que...”. Pronto. Está iniciado todo o processo de construção da pseudo-identidade dessa criança, que vai tomando proporções tais que tudo o que ela faz ou o que acontece com ela serve para comprová-lo, expandi-lo, até que se estabeleça sua incrustação naquele ser humano.

Assim, confinados e congelados nas posições estabelecidas por $\mathrm{A}$ e J, CH não consegue dimensionar todos os seus recursos e suas potencialidades e N também não procede de modo diferente. Ele está fadado a ser um homem que tem de tirar da mente as soluções, as idéias, como se possuísse o dom das ciências infusas. Mas quem as têm? Todas as pessoas precisam estudar e trabalhar muito seus conhecimentos, se quiserem entender alguma coisa. 
Então, se $\mathrm{N}$ agir do mesmo modo que $\mathrm{CH}$, também ficará incapacitado para se desenvolver, tendo que operar um processo de crescimento miraculoso, um crescimento que chega às raias de uma realidade impossível, pois não fica, em nenhum momento, de posse e nem faz uso dos recursos e das potencialidades que poderia ter à sua disposição.

O pai, ninguém vê. A mãe funciona como eixo. Ela não quer, mas quer, ao mesmo tempo. Ora, se fosse tirada dessa posição, como ela se experimentaria? Oue dimensão impregnaria a ela própria, depois de tantos anos?

É por todos esses motivos que o estudo desse grupo familiar se torna tão interessante. E um grupo antigo que, quando chega a uma sala de terapia, traz uma história mais antiga ainda, iniciada na geração anterior. Os papéis dentro dele estabelecidos estão de tal forma cristalizados que as pessoas não se mexem nesse grupo. As pessoas se subjugam: o irmão brilhante subjuga o irmão incapaz que, por sua vez, o admira e o elege como o irmão brilhante. Todos concorrem para ficar onde estão, congelando-se a si e ao outro. É por isso que a situação fica imutável.

A trama não pára de se movimentar, gerando um terceiro produto que gere todos os componentes do grupo, submetendo-os, pois esse produto é mais forte que cada elemento por si. E isso não se dá somente num grupo familiar, mas em qualquer grupo a que se pertença. $O$ produto de sua trama se arrasta e seu resultado segue uma direção que nada mais tem a ver com cada pessoa inserida nesse grupo e na medida em que se forma uma teia, é mais forte do que todas elas. Tem-se, aqui, um conceito de sistema trazido da biologia. Não é meramente uma teoria, mas um método para se compreender os fenómenos e, neste estudo, está sendo utilizado como subsídio à teoria analítica, extraída da psicanálise, para que se compreenda profundamente as relações familiares.

Num relacionamento de família, existe o afeto, o amor e a teia, e entre esses dois elementos há uma profunda relação na medida em que, apesar de todos os membros componentes da família se amarem muito, a qualidade do amor a ser nela veiculado está afetada por essa teia.

O ciclo de vida de uma família assemelhase ao ciclo de vida de uma planta. Começa com uma parelha humana, ou seja, o namoro, seguido de noivado e casamento. Nascem os filhos, crescem, vão para a escola, chegam à adolescência, vão para a fase adulta. Então, os filhos saem do seio familiar, o casal torna a ficar sé e o ciclo se encerra. É perfeito como o ciclo de uma planta, ou de qualquer organismo vivo.
Porém, esse ciclo exerce fortíssima influência sobre a teia, posto que esta se desenvolve paralelamente àquele. A vida e a realidade invadem essa trama de tal forma que a família não consegue sobreviver em algum momento deste ciclo.

Observe-se o exemplo a seguir: Um casal, pais de gémeos, um menino e uma menina, procurou a ajuda de uma terapia de casais. Na sessão, constatou-se que as brigas do casal começaram por ocasião da gravidez da mulher.

Ela é filha caçula e temporã, a irmã, imediatamente acima dela, tinha 17 anos quando do seu nascimento. Seu pai era piloto e se ausentava por largos e longos períodos, o irmão mais velho tinha 23 anos. Sua mãe criou-a de forma a ter por ela quase que um compromisso de sobrevivência, pois suportou um casamento muito frustrante, o marido sempre ausente, os filhos já moços, mas, mesmo assim, teve essa filha.

O homem do casal em questão foi o filho mais velho de uma família cuja mãe ficou viúva prematuramente, tendo ele, aos 17 anos de idade, de assumir o papel de chefe, tomando conta da mãe e de toda a família.

Aparentemente, este era o homem ideal para aquela mulher, pois daria total cobertura a sua fragilidade, de modo que ela prosseguisse na vida mantendo a mesma posição mental que ela tinha na própria família.

Enquanto os filhos não apareceram, o casamento funcionou, pois ela o tinha à disposição e ele também.

A partir do nascimento dos gémeos, ainda mais de um menino e uma menina, o casamento desmoronou, pois não houve continência para as circunstâncias criadas. A família não conseguiu superar um ciclo. A trama foi mais forte.

Veja-se, agora, outra situação: A família de um político procurou auxilio da terapia. Havia sete pessoas nesse grupo: 0 pai, a mãe e cinco filhos, dos quais sé um do sexo masculino.

O marido sempre estava ausente, mas a mãe conseguiu se $\mathrm{de}^{\wedge} \sin ^{\wedge} \mathrm{C}^{\wedge} \mathrm{umbir}$ de sua tarefa, sem problemas. Levava os filhos à escola, depois cuidava de seus deveres; os dois mais novos ainda eram bebés e ela pôde controlar a situação.

O problema se tomou claro, quando as duas filhas mais velhas atingiram a adolescência-época em que a família procurou a terapia — $\operatorname{com~} 17$ e 14 anos. Nesse período, geralmente se faz necessária a presença masculina, que exerça um controle o a vida social. A mãe tem esse controle e nunca ousou tocar nos conflitos ou mexer na situação de conflito que tinha com 0 mando. Então, durante a sessão, ela reclama da filha mais velha: "Ela diz que chega às 10 , mas ela sai às 10 e diz que chega às 2 , mas ela não chega às 2 , ela chega às 3 e meia”. 
Sabe-se, entretanto, que, atualmente, os programas começam às $23 \mathrm{~h}$, portanto, se 0 adolescente chegar às 3:30, estará dentro do período da normalidade, pois, anos atrás, saía-se às 20 h e chegava-se à meia-noite. É somente uma questão de adaptação.

Mas não para a mãe em questão: "Eu entro, fico desesperada, ele não está, ele nunca está e ele não pode estar, sempre com compromissos aqui, ali e acolá. Eu fico tão desesperada, tão desesperada, que eu vou pró cama e eu chego a dormir, dormir, dormir, dormir e dormir. Eu não sei o que fazer".

É realmente uma situação que se sustentou até agora, mas, se o sis ema e a teia que regem essa família não forem redefnidos podem romper, o que seria muito difícil para essa mãe, pois, mesmo com esse suposto rompimento, ela poderá não conseguir o que precisa. Ao contrário. Dependendo da situação, um rompimento traria para ela desdobramentos ainda piores.

Pode-se entender uma situação, mas é a família que tem os componentes, e os tem mesmo para, através do descongelamento dessa teia rígida, achar novas soluções.

Buscando-se um melhor entendimento do tema em questão, pode-se afirmar que o desejo de amar uma criança não é soberano, nem hegemônico. Depende das possibilidades de maior ou menor expansão a que ele está submetido. Esta teia sofre pressões da própria realidade, por vezes até de forma dramática.

Assim, depois de definida a importancia do papel não-aparente, real, que cada elemento tem numa família, na permanência desse sistema, percebe-se, claramente, que um falo, desestruturador de uma família, possa não desestruturar necessariamente outra. Exemplo: Uma família de quatro elementos foi procurar ajuda na terapia. Era composta por três filhos e pela mãe, viúva. A filha mais velha tinha 31 anos, seguida por outra de 27 , as quais já haviam se casado, desquitado e tornado à casa paterna, juntamente com seus filhos. O único filho homem, apesar de não morar com a mãe, depende economicamente dela.

Os membros desse grupo familiar estavam tão profundamente ligados e eram tão interdependentes que a sessão foi marcada com todos.

A causa-base da procura da terapia foi o alcoolismo da mãe, $\wedge^{\wedge} \mathrm{O}^{\wedge}$ oerador de muitas brigas na família.

Quando, porém, realmente tudo começou? Quando da doença do pai. Ele sempre representou, nesta família, o mesmo papel que a mãe anteriormente analisada. Sobre ele estavam coloca- dos os recursos e as possibilidades de cada elemento da família: o poder gerir, suportar e conduzir a própria vida. Todos o viam como uma figura idealizada, dar o deslocamento maciço de recursos, sem os quais ninguém vive e que estão dentro das pessoas.

Mas, dependendo do movimento mental que se faça, o processo mental instalado fica para o outro. Então, quando este some, acontece a tragédia, uma vez que ele levou consigo todos os recursos de que se disporia e se teria de dispor para se cuidar da sobrevivência.

A filha de 31 anos desquita-se e volta à casa paterna com um filho. A outra, de 27 anos, também se desquita e retorna, com dois filhos. O pai foi ficando sem saída e, em seis meses, morre, vitimado por um cancer. Parece que ele, não aguentando, sucumbiu. E, com ele, todos sucumbiram.

Sabe-se, contudo, que não é toda família que sucumbe com a perda do pai, pois não é toda família que tem sistemas instalados de tal forma que as posições de seus membros congelem-se e fixem-se a esse ponto. Mas a realidade, quando alua, encontra, pois, na família, maior ou menor possibilidade de metabolizar o fato de, efetivamente, se pulverizar com o fato.

Há o caso de um outro casal, cujo marido também trazia um quadro de alcoolismo, agravado por hipertensão. Seu clínico, com rara visão psicossomático, aconselhou: "Olha, eu acho interessante que vocês façam uma terapia de casal”.

Então, através de uma enorme briga, na primeira sessão, a situação foi apresentada: o rapaz era filho mais velho, dentro da família, e carregava em seus ombros o pai, a mãe e uma irmã, além do seu próprio grupo familiar, composto pela mulher e pelo filho. Além disso, também se tomou protetor do sogro e da sogra.

$E$ assim que a pessoa vai entrando num ajustamento, agarrando-se a uma incrustação e conduzindo a vida, sem se indagar da qualidade e da natureza das suas reais possibilidades. E, às vezes ao arrancar a incrustação, não aguenta. Pois, sem se $\operatorname{desma} \wedge^{\wedge} \mathrm{s}^{\wedge}$ carar $\sim$ ela não sabe se vai resistir. Há uma espécie de fusão e é aí que ela se dimensiona: naquilo que de falo ela poderia ter como expansão.

Exatamente nessa medida é que a história clínica é de suma irnportância: para se considerar uma criança, deve-se considerar sua história e para se considerar um sistema de inter-relações, deve-se compreender a posição de cada um, dentro desse sistema.

É como se, ao se escutar uma orquestra, se pudesse dela extrair o solo de clarinete que nela está inserido. Apagar-se-ia, totalmente, o resto da orquestra, num aparelho de som. Somente o solo de clarinete seria executado. E, nesse momento, é 
que se perceberia que ele tem vida própria, seu próprio som, suas próprias notas e nuances. E, somente depois dessa plena percepção é que a orquestra seria novamente incluída, para acompanhar o solo do clarinete.

Fica-se, enfim, com a certeza de que a faculdade de amar, essa qualidade, é um dom inato.

\section{BIBLIOGRAFIA}

1. ANDOLFI, M. A família como sistema de interação. In: A Terapia Familiar. Lisboa, Vega, 1981, pp. 19-23.

2. FREUD, S. La Interpretación de los Sueños. Tomo 1, Madrid, Biblioteca Nueva, 1973.

3. VON BERTALANFFY, B. O significado da
Todos têm amor. E todos têm ódio...

Dependendo da composição a que se entregam, as pessoas podem usar esse amor em maior ou menor possibilidade, para ser oferecido mesmo a elas próprias, porque o exercício de amar faz muito bem. Principalmente quando se vai oferecê-lo a quem está próximo...

teoria geral dos sistemas. In. Teoria Geral dos Sistemas. Petrópolis, Vozes, 1973, p. 5.

4. KLEIN, M. O significado das primeiras situações de angústia no desenvolvimento do ego. In: Psicanalise da Criança. São Paulo, Mestre Jou, 1975, pp. 237-257.

5. PAPP, P. El dilema del cambio. In: El Processo del Cambio. Buenos Aires, Pardós, 1988, pp. 20-28. São Paulo - SP. 